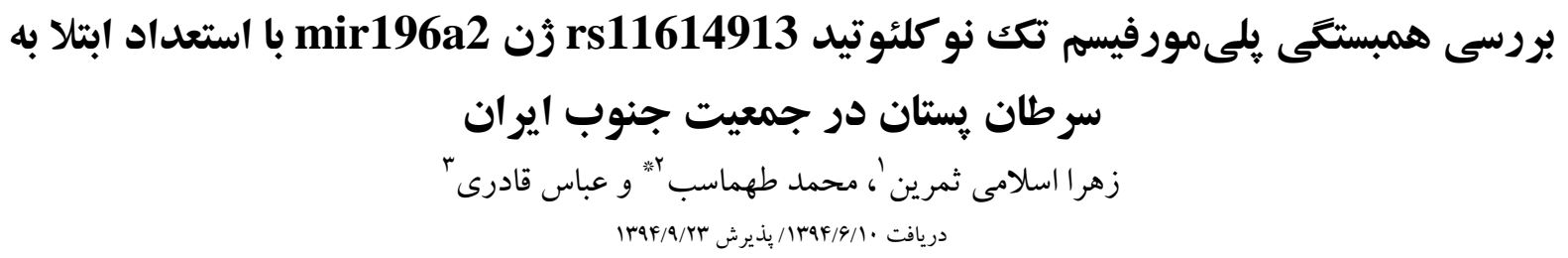

$$
\begin{aligned}
& \text { اكروه علوم سلولى و مولكولى، يرديس بين الملل دانشكاه خوارزمى،كرج }
\end{aligned}
$$

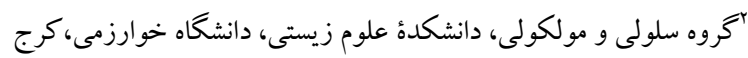

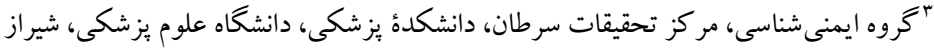

tahmaseb@khu.ac.ir مسئول مكاتبات

جكيده. سرطان يستان شايعترين سرطان در دنيا و دومين علت مرگكومير يس از سرطان ريه در زنان مىباشد. ميزان شيوع سرطان پستان در كشورهاى آسيايى مانند

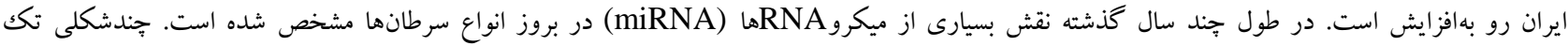

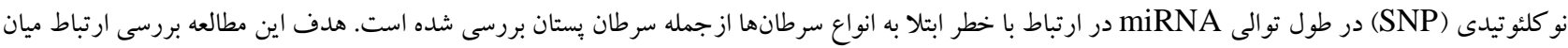

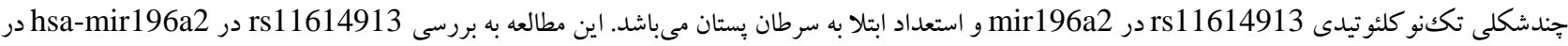

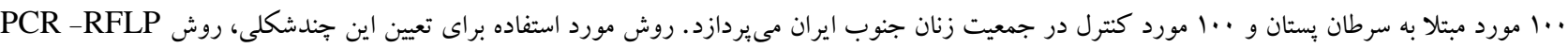

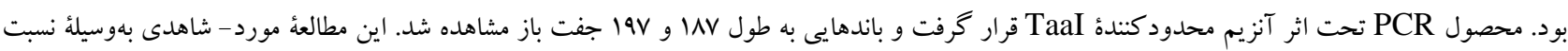

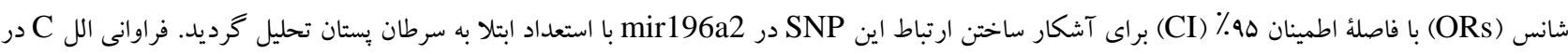

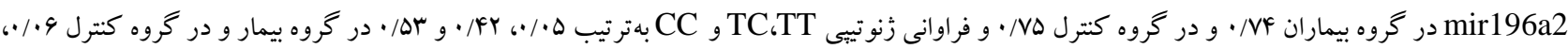

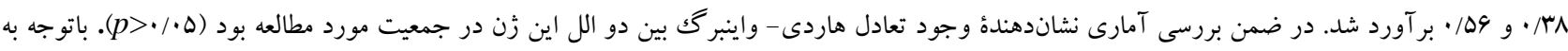

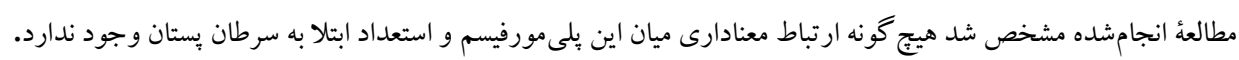

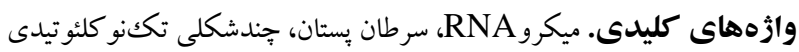

\title{
Evaluation of single nucleotide polymorphism rs11614913 in mir196a2 with breast cancer susceptibility in Southern Iranian population \\ Zahra Eslami-Samarin ${ }^{1}$, Mohammad Tahmaseb ${ }^{2 *}$ and Abbas Ghaderi ${ }^{3}$ Received 01.09.2015 / Accepted 14.12.2015
}

\footnotetext{
${ }^{1}$ Department of Cell and Molecular Sciences, International Pardis, Kharazmi University, Karaj, Iran ${ }^{2}$ Department of Cell and Molecular Sciences, Faculty of Biological Sciences, Kharazmi University, Karaj, Iran ${ }^{3}$ Department of Immunology, Institute for Cancer Research, Shiraz University of Medical Sciences, Shiraz, Iran *Correspondent author: tahmaseb@khu.ac.ir
}

\begin{abstract}
Breast cancer is the most common cancer worldwide and is the second leading cause of death in women after lung cancer. Micro RNAs (miRNAs) are among endogenous factors which are involved in many types of cancers, including breast cancer. Single nucleotide polymorphism (SNP) in the miRNAs, might change their biological activities such as their effects on oncogenes and tumor suppressor genes. Therefore some of miRNA's SNPs are associated with the risk of different types of cancer, including breast cancer. The aim of this study was to evaluate the correlation between SNP rs11614913 in mir196a2 and the risk of breast cancer. SNP rs11614913 in hsa-miR-196a2 analyzed in 100 breast cancer cases and 100 controls in women living in southern Iran. Polymorphism was identified by the PCRRFLP method. The PCR product was digested with TaaI restriction enzyme which produced two bands with the length of $187 \mathrm{bp}$ and 196bp. The data from this case -control study were analyzed using odds ratios (ORs) with $95 \%$ confidence intervals (CIs) to reveal the associations of SNPs in miRNAs with breast cancer susceptibility. The C allele frequencies in patients and controls for miR-196a 2 were 0.74 and 0.75 , respectively. The genotype frequencies of TT, TC, and CC were $0.05,0.42$, and 0.53 for the patients and $0.06,0.38$, and 0.56 for the controls, respectively. Statistical analysis showed that the genetic frequencies for this SNP were in Hardy-Weinberg equilibrium ( $>>0.05)$. The results of this study indicated no significant association between SNP rs11614913 in mir196a2 and the risk of breast cancer.
\end{abstract}

Keywords. microRNA, breast cancer, polymorphism 
mir196a2 يكى از انواع miRNA است كه اخيراً مطالعات

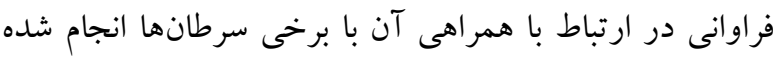

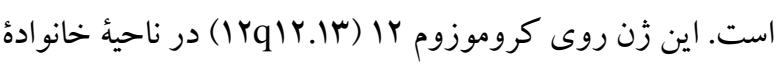
رنى Homeo box C (HOXC) در زنوم مهرهداران قرار دارد

.(Chen, 2011)

از عوامل موثر بر عملكرد miRNA مىتوان به وجود جند-

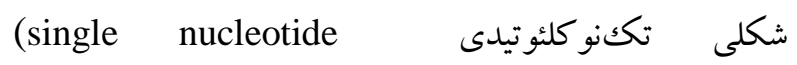
(polymorphism

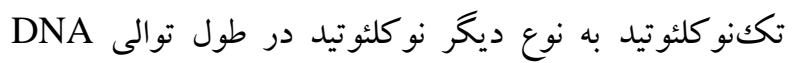

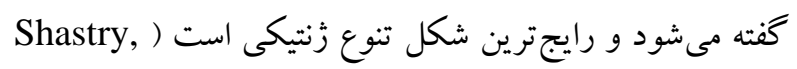

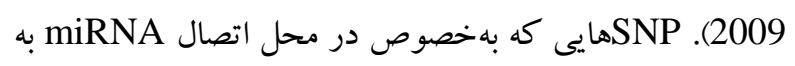

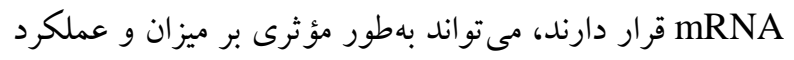
نهائى miRNA تأثير كذار باشند. حضور

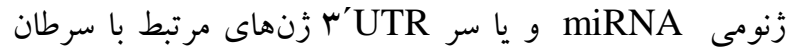
مى تواند با تغيير تنظيم وابسته به miRNA، در استعداد ابتلا به سرطان موثر باشند (Fabbri et al., 2009). اين واقعيت كه فراوانى SNP در جمعيتهاى مختلف، متفاوت است محققين را بر آن داشته است تا نسبت به تعيين فراوانى يكك خاص و همراهى آن با بروز به يكك بيمارى خاص،

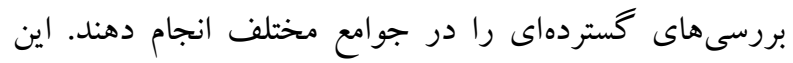

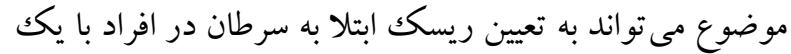
رنوتيّ خاص در SNP مورد مطالعه منجر شود. جندشكلى تككنو كلئوتيدى rs11614913 در ناحئ

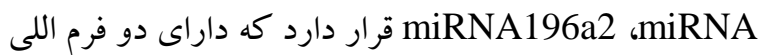

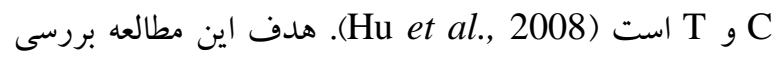

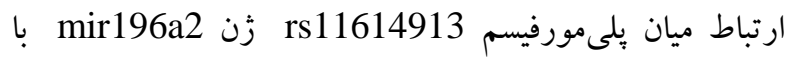
ابتلا به سرطان بـتان است.

\section{مواد و روشها جمع آورى نمونه}

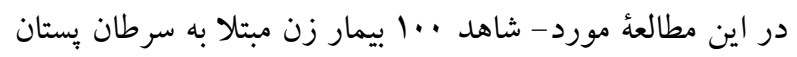

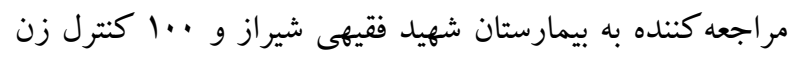

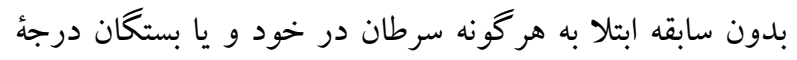

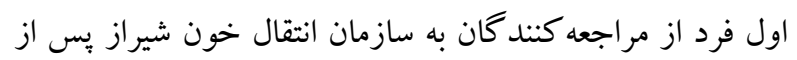

سرطان بِستان شايع ترين سرطان در جهان و دومين علت مرك و

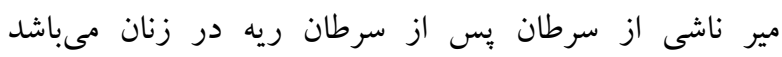
(Dumitrescu \& Cotarla, 2005)

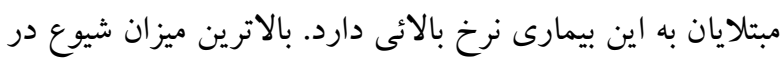

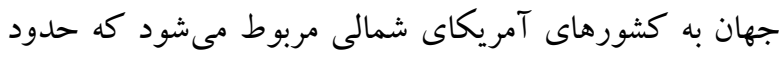
99/؟ در هر ... هزار نفر است (Sadjadi et al., 2009).

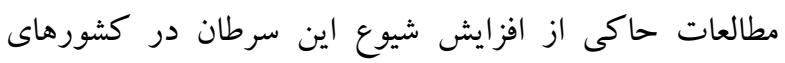

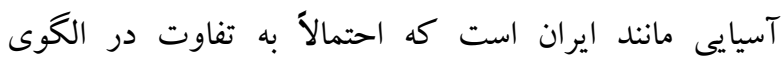

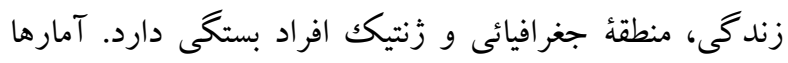

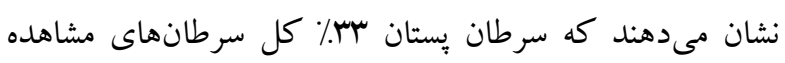
شده در زنان و مسئول 19٪ مر گكومير ناشى از سرطان در آنهان

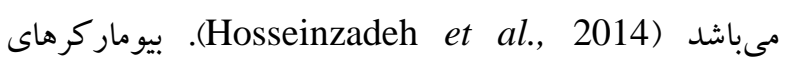
زيستى و استفاده از آنها نقش مهمى در رابطه با تشخيص

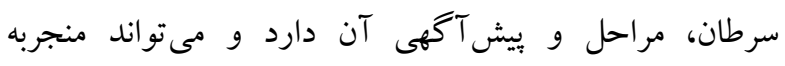

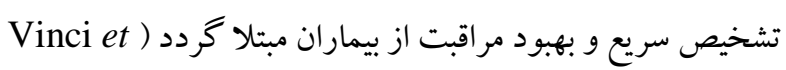
.(al., 2011 هاى غير كد كنتده به طول YRNA ،miRNA

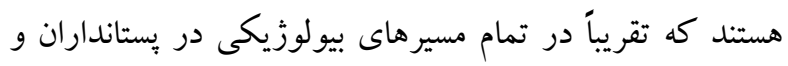

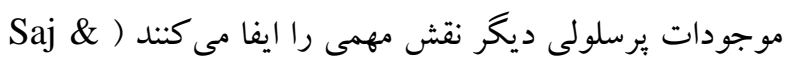

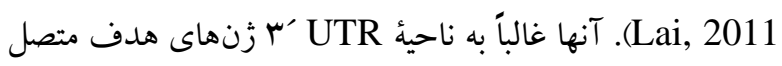

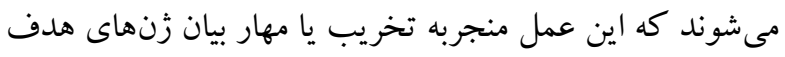

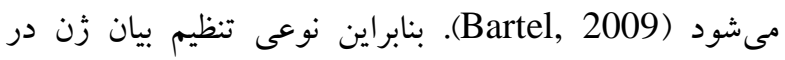
مرحلة پِس از رونويسى است (Filipowicz et al., 2008). برخلاف mRNA كه فقط توانائى تعامل با تعداد محدودى miRNA را دارد، يك miRNA توانائى اتصال به هزاران نسخه متفاوت LRNA را دارد (Lewis et al., 2005). هاى ساختهده از هر زن ازجمله آنهايى كه از

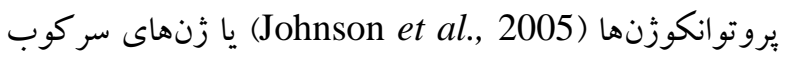
كنندة تومور (Visone et al., 2007) ساخته مىشوند بهطور

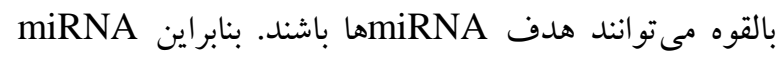
نقش مهمى در سازو كار مرتبط با تومورزايى و متاستاز سلولهاى تومورى ايفا مى كنند (Garzon et al., 2009). 
آنزيم TaaI و 9 ميكروليتر از ddH2O تهيه و در دماى 90

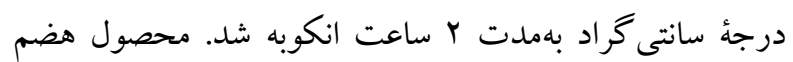

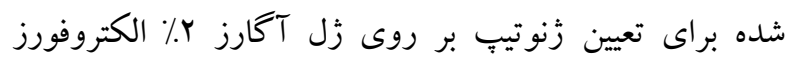

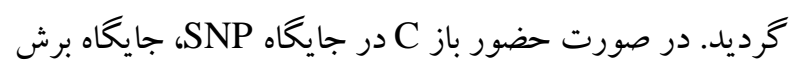

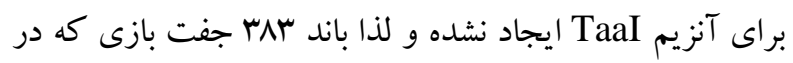
واقع اندازة محصول PCR است مشاهده مىشود. درصورت

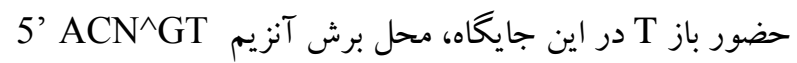

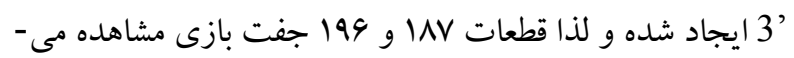

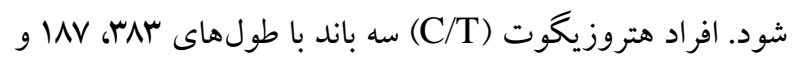
199 جفت باز ايجاد مى كنند كه البته بهعلت نزديكى اندازهُ دو قطعة 1NV و 199، تنها دو باند قابل مشاهده خو اهد بود

نتايج

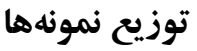

در اين مطالعه ..1 بيمار زن مبتلا به سرطان بِ بـتان كه ميانكين

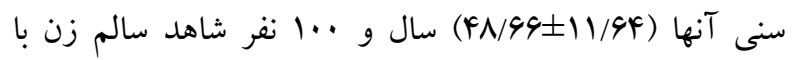

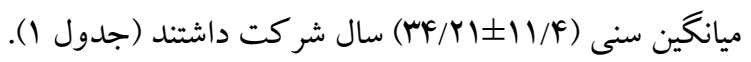

\section{تخليص DNA و تكثير خن miR196a2}

مقدار A260/A280 براى DNAى تخليص شده در محدودة

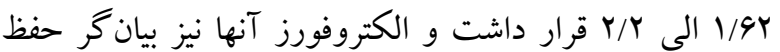
تماميت مولكولهاى DNA بود. همجنين طول قطعه تكثيرشده

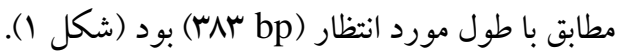
هضم آنزيمى نمونه هاى تكثير شده براى تعيين الكوى اللى نمونههاى مورد مطالعه، حدود

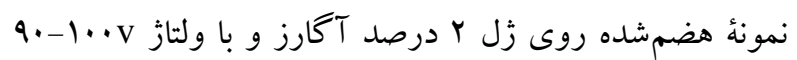

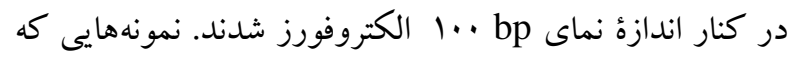

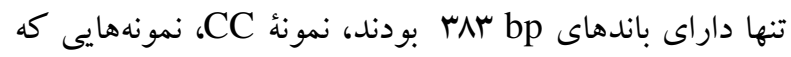

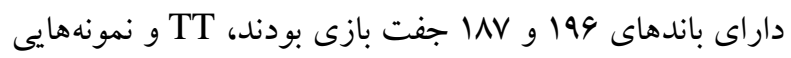

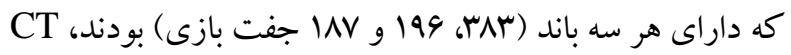
محسوب شدند (شكل ()).
تكميل برسشنامه و رضايتنامه كتبى آكاهانه مورد بررسى قرار گرفتند. هر دو گروه از نظر مشخصات سن، جنس و من منطقه جغر افيايى با يكديخر مطابقت داشتند.

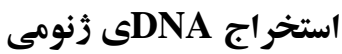
در اين مطالعه استخراج DNA بهروش خارجسازى نمكى انجام شد. Miller et al., 1988) ازنظر كيفى و هم ازنظر كمى به روش الكتروفورز و نورسنجى مورد بررسى قرار گرفت. تكثير زن mir196a2 - m زن mir196a2 با استفاده از يرايمرهاى اختصاصى تكثير شد

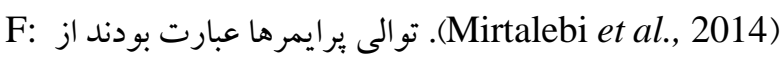
R: , TAGG 5': GTCTACTCTCTAGTCC PCR واكنش ThGAGAGGACGGCATAAAGC در حجم نهايى ه ميكروليتر با استفاده از إه/ إميكرو محلول

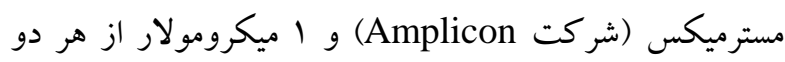

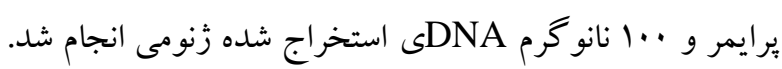

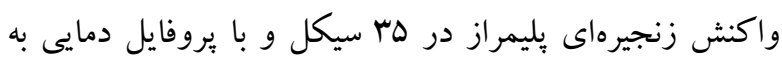

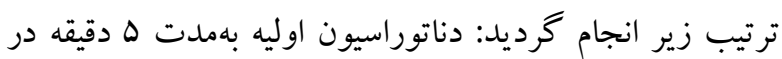

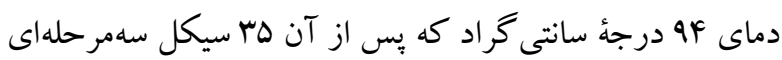

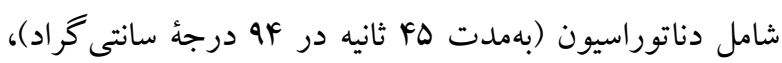
اتصال يرايمر به هدف (بهمدت •F ثانيه در دماى 9N/ درجهُ

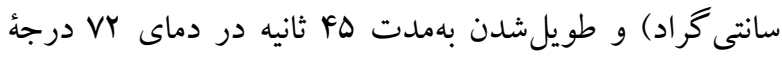

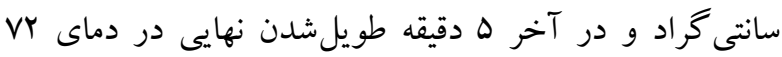

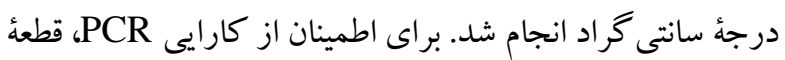

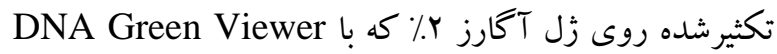
رنخگ آميزى شده بود، الكتروفورز گرديد.

تعيين زنوتيب mir196a2

براى تعيين زنو تيبهاى حاصل از يلى مورفيسم از روش RFLP استفاده شد. محصول PCR تحت اثر آنزيم محدودكندة TaaI شركت Fermentas قرار كرفت. براى واكنش هضم آنزيمى، محلولى حاوى •اميكروليتر محصول

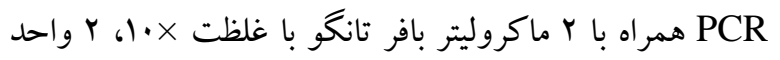


جدول ا-توزيع سن در دو گروه بيمار و شاهد.

Table 1. Age distribution in patient and control groups.

\begin{tabular}{|c|c|c|c|}
\hline & Patients & Control & $\mathrm{p}$-value \\
\hline Variables & $\mathrm{n}=100$ & $\mathrm{n}=100$ & \\
\hline Age $($ years $)($ mean $\pm S D)$ & $48.6 \pm 11.6$ & $34.5 \pm 11.5$ & $<0.001$ \\
\hline Age(years) & $\mathrm{n}(\%)$ & $\mathrm{n}(\%)$ & \\
\hline$>55$ & $28(0.28)$ & $8(0.8)$ & 0.0002 \\
\hline$<55$ & $72(0.72)$ & $92(0.92)$ & \\
\hline
\end{tabular}

Gender

Female

100

100

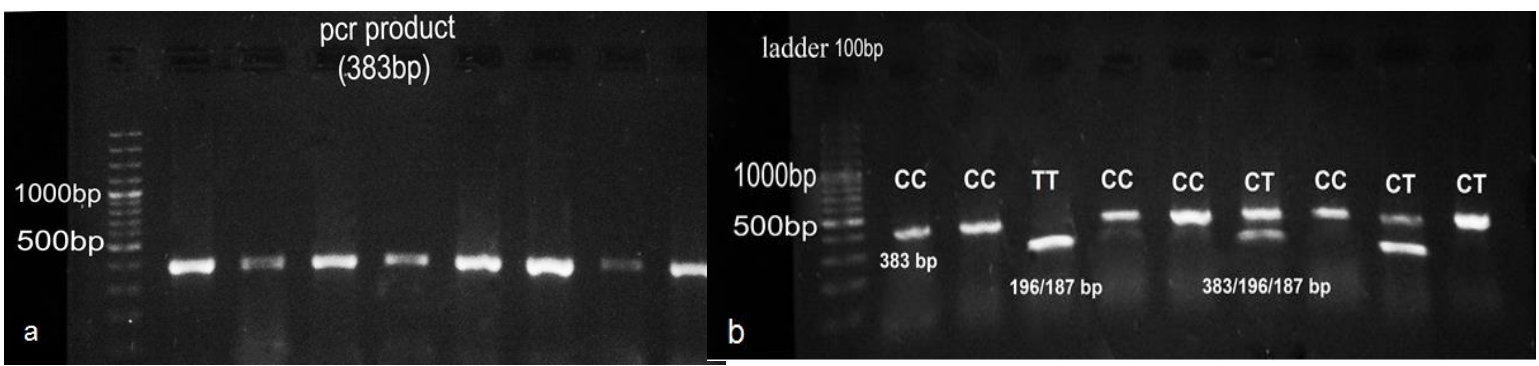

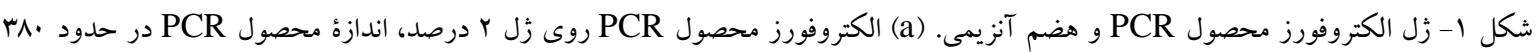

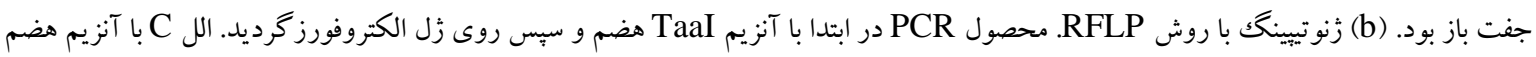

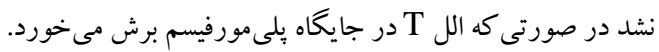

Fig. 1. Gel electrophoresis of PCR and enzyme digestion. (a) Running the electrophoresis of PCR products on $2 \%$ gel.The size of PCR product was around 380 bp (b) RLFP genotyping. The PCR products were digested by Taal restriction enzyme and then run on the gel. Allele $\mathrm{C}$ was not digested with enzyme while allele $\mathrm{T}$ was cut at polymorphis site.

بررسى هاى آمارى نشان داد كه فراوانى زنوتيبى در هر سه گروه بيمار، شاهد و كل در تعادل هاردى-واينبرگك قرار دارند

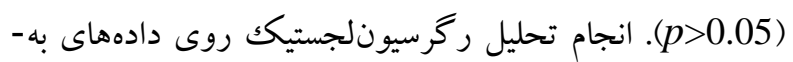
دست آمده نشانداد كه تفاوت قابل ملاحظهاى بين زنوتيبٍهاى TT و CT ،ين افراد بيمار و شاهد وجود ندارد (شكل Y). بررسى مدل غالبيت و مدل مغلوبيت نيز فاقد تفاوت معنىدار بين افراد بيمار و شاهد بود. دستهبندى افراد بر حسب سن (بيشتر و كمتر از ها سال) نيز نتيجهُ مشابهى داشت (جدول Y).

\section{فراوانى ذنوتييى و اللى}

بررسى الكوى هضم آنزيمى نشانداد كه زنو تي״ CC در SNP

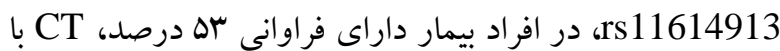
فراوانى Fr درصد و TT با فراوانى ه درصد است. فراوانى زَنوتيٍ سه كانهُ فوق در همين جايگاه در افراد شاهد بهترتيب

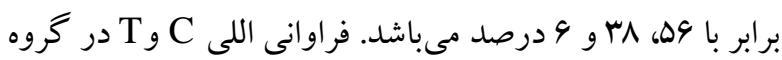

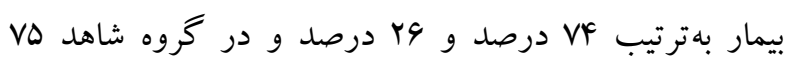
درصد و هr درصد بود. فراوانى زنوتيى CC و CT CT نيز در كل جمعيت مورد مطالعه بهترتيب ه/D/Dا، ·F و م/ه درصد بود. 
جدول r- فراوانى اللى و زنوتييى زُن يلى مورفيسم mir196a2 دs11614913 در بين افراد بيمار و شاهد و بررسى همراهى اين SNP با خطر

ابتلا به سرطان بـتان.

Table 2. Allelic and genotypic frequencies of rs11614913 in mir196a2 in patient and control individuals and determination of association between this SNP and breast cancer susceptibility.

\begin{tabular}{|c|c|c|c|c|c|}
\hline \multirow{2}{*}{ Variables } & \multicolumn{4}{|c|}{$\mathrm{n}(\%)$} & \multirow{2}{*}{$P$-value } \\
\hline & Genotypes & Patient $(n=100)$ & Control(n=100) & $\mathrm{OR}(95 \% \mathrm{CI})$ & \\
\hline \multirow[t]{7}{*}{ Total } & $\mathrm{T}$ allele & $52(26)$ & $50(25)$ & 1 & \\
\hline & $\mathrm{C}$ allele & $148(74)$ & $150(75)$ & $1.05(0.67-1.65)$ & 0.92 \\
\hline & $\mathrm{TT}$ & $5(5)$ & $6(6)$ & 1 & 0.83 \\
\hline & $\mathrm{TC}$ & $42(42)$ & $38(38)$ & $0.75(0.21-2.67)$ & \\
\hline & $\mathrm{CC}$ & $53(53)$ & $56(56)$ & $0.88(0.25-3.05)$ & \\
\hline & TTvsTC/CC & $95(95)$ & $94(94)$ & $0.82(0.24-2.79)$ & 1 \\
\hline & CCvsTC/TT & $47(47)$ & $44(44)$ & $0.88(0.5-1.54)$ & 0.78 \\
\hline \multicolumn{6}{|l|}{ Age (year) } \\
\hline \multirow[t]{7}{*}{$>55$} & $\mathrm{~T}$ allele & $15(27)$ & $7(43.75)$ & 1 & \\
\hline & $\mathrm{C}$ allele & $39(73)$ & $9(56.25)$ & $0.49(0.15-1.5)$ & 0.37 \\
\hline & TT & $1(3.7)$ & $1(12.5)$ & 1 & 0.4 \\
\hline & $\mathrm{TC}$ & 13(48.1) & $5(62.5)$ & $0.38(0.02-7.04)$ & \\
\hline & $\mathrm{CC}$ & 13(48.1) & $2(25)$ & $0.15(0.006-3.57)$ & \\
\hline & TTvsTC/CC & $26(96.2)$ & $7(87.5)$ & $0.27(0.01-4.86)$ & 0.92 \\
\hline & CCvsTC/TT & $14(51.8)$ & $6(7.5)$ & $2.78(0.47-16.34)$ & 0.78 \\
\hline \multirow[t]{7}{*}{$<55$} & $\mathrm{~T}$ allele & $37(25.3)$ & $43(23.3)$ & 1 & \\
\hline & $\mathrm{C}$ allele & 109(74.6) & 141(76.6) & $1.11(0.67-1.84)$ & 0.67 \\
\hline & $\mathrm{TT}$ & $4(5.47)$ & $5(5.43)$ & 1 & 0.87 \\
\hline & $\mathrm{TC}$ & $29(39.7)$ & $33(35.8)$ & $0.91(0.22-3.7)$ & \\
\hline & $\mathrm{CC}$ & $40(54.7)$ & $54(58.6)$ & $1.08(0.27-4.27)$ & \\
\hline & TTvsTC/CC & $69(94.5)$ & $87(94.5)$ & $1.008(0.26-3.89)$ & 0.74 \\
\hline & CCvsTC/TT & $33(45.2)$ & $38(41.3)$ & $0.92(0.49-1.72)$ & 0.73 \\
\hline
\end{tabular}

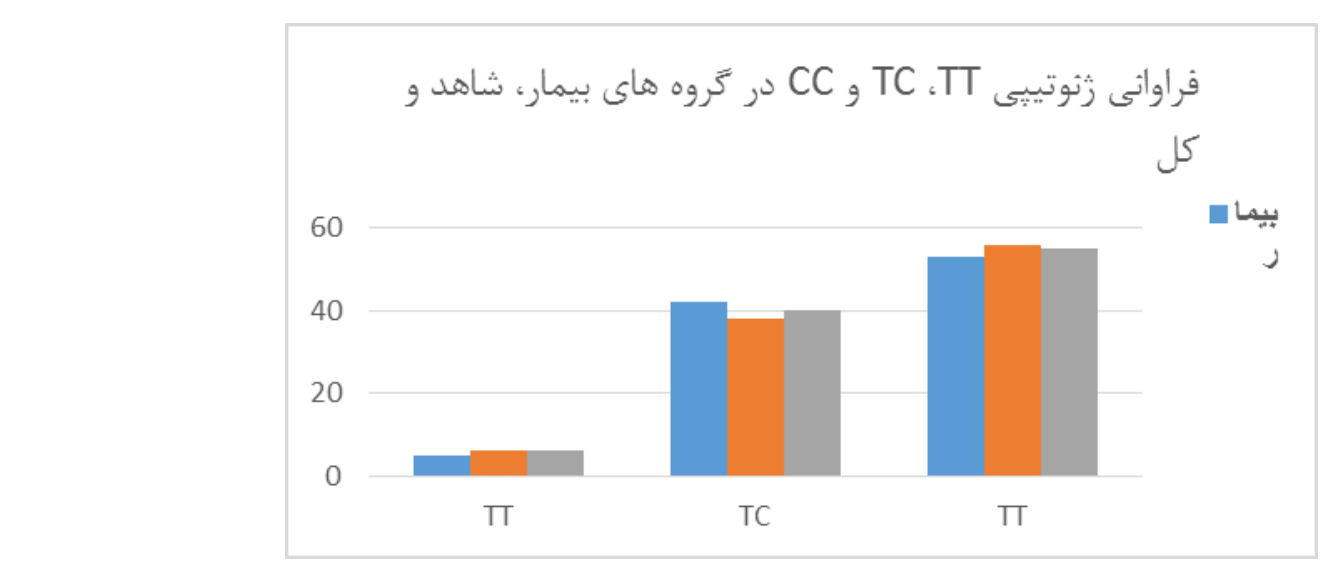

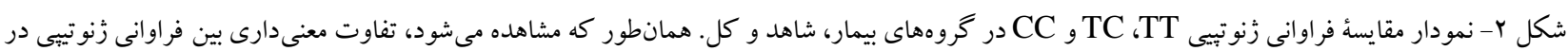
كروههاى فوق وجود ندارد.

Fig. 2. Comparison between genotype frequencies of TT, TC and CC in patient, control and total groups. There were no significant differences between genotype frequencies among these three groups. 
مطالعات در جوامع ديخر بيان گر جنين ارتباطى است. براى مثال Hu

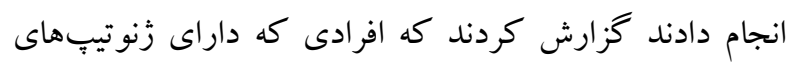

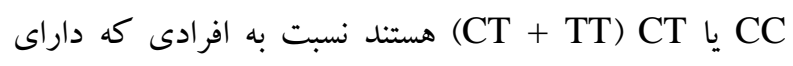
زنوتيب TT هستند، درمعرض خطر بيشترى براى ابتلا به سرطان

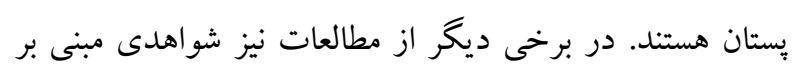

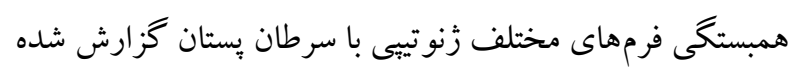
است (Gao et al., 2011; Linhares et al., 2012). اين درحالى است كه در دو جمعيت آلمانى و ايتاليايى اين همبستخى مورد تأييد قرار نغخرفت (Catucci et al., 2010). بررسى دادهاى جمعيتى اين ايده را مطرح مى كند كه تأثير

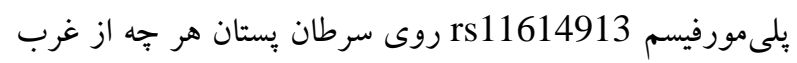
به سمت شرق حركت مى كنيم، بيشتر مى شود. در اين راستا به-

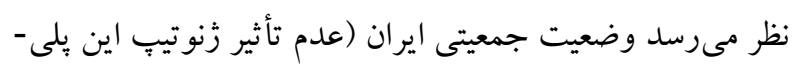
مورفيسم روى بيمارى) مشابه جمعيت هاى ارويايى است.

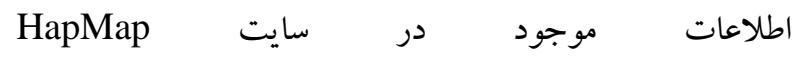
） (/http://hapmap.ncbi.nlm.nih.gov) فراوانى اللهاى C و T با سه جمعيت ناحيه Southwest در

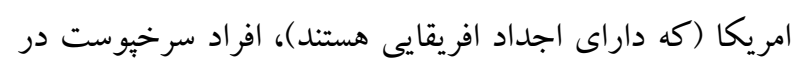

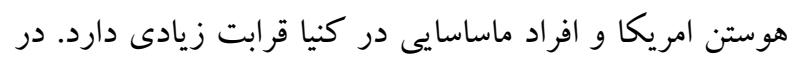
ساير جمعيت هاى مورد مطالعه (به خصو جميعت جينى و زاينى) اين تفاوت حداكثر است. در بررسىهاى بعدى تأثير حضور

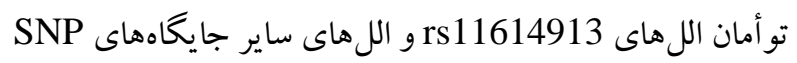

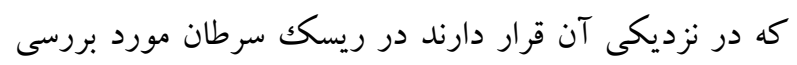

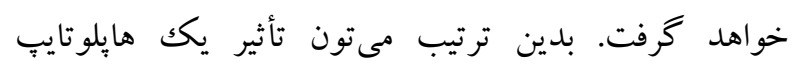
مشخص را با ريسك بيمارى تشخيص داد.

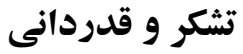

اين مطالعات با حمايت مركز تحقيقات سرطان دانشگاه علوم

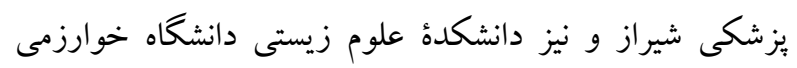
صورت گرفته است. از آقاى مهيار ملككزاده (مركز تحقيقات سرطان) براى همكارى در اين بروزةه و بازخوانى متن مقاله

$$
\text { قدردانى مىشود. }
$$

سرطان بهعنوان سومين عامل مرگكومير در ايران درنظر خرفته

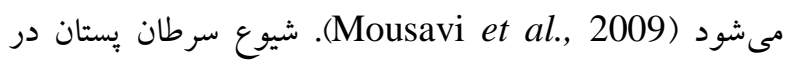
زنان يككسوم كل سرطانها و دومين سرطان رايج بعد از سرطان

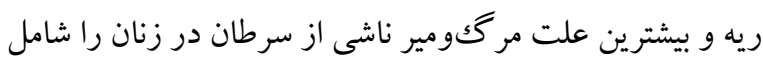

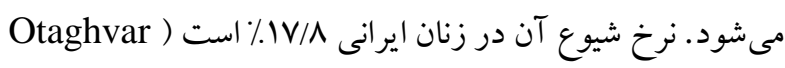

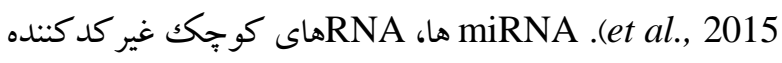

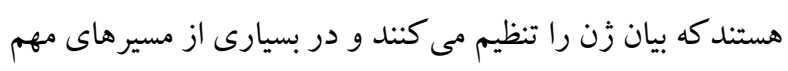

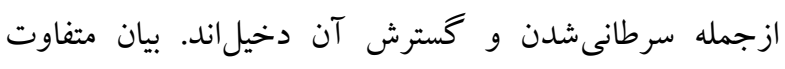
ها در برخى از حالات باتولوزيكك از جمله سرطانها،

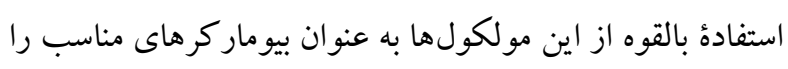

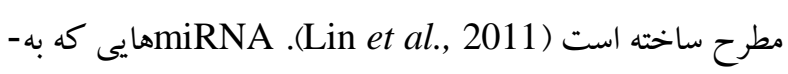
طور معمول كنترل بيان انكوزنها را كنترل مى كنند در صورتى كه عملكرد خود را از دست دهند (جهش از دست رفتن

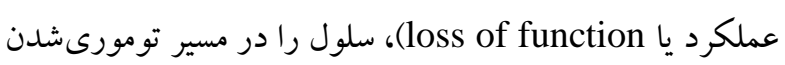
يشي مىبرند. آنهايى كه بيان زنهاى سر كوب كنندهى تومور را

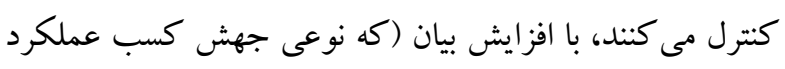

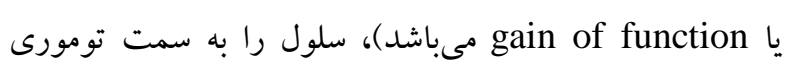
شدن هدايت مى كنند. در اين دو حالت miRNA نقش انكورنى

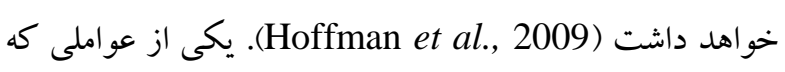

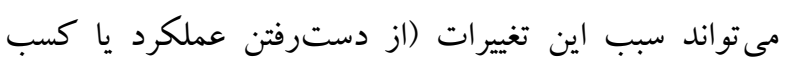
عملكرد) در زن miRNA شود، تغيير در توالى آن و از جمله آنه

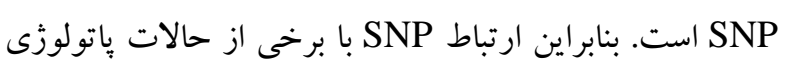

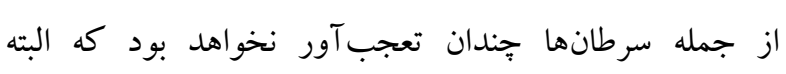

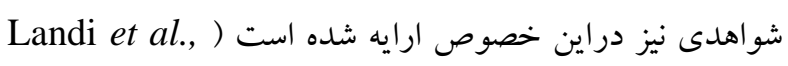
2012). برخى از مطالعات نشان داده است كه دئ يلى مورفيسم

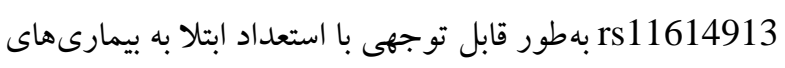

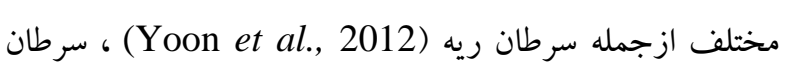
سينه (Landi et al., 2008)، سرطان معده ( Okubo et al.,

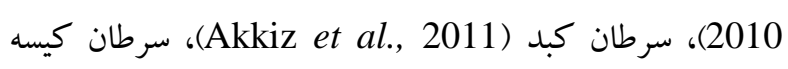
صفرا (Srivastava et al., 2010)، سرطان بروستات Wang et al., ) و سرطان مرى (George et al., 2011)

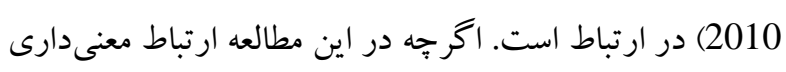

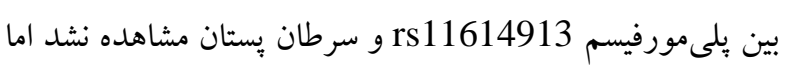




\section{References}

Akkiz, H., Bayram, S., Bekar, A., Akgollu, E. and Ulger, Y. 2011. A functional polymorphism in premicroRNA-196a-2 contributes to the susceptibility of hepatocellular carcinoma in a Turkish population: a case-control study. - J. Viral Hepat. 18: e399-407.

Bartel D.P. 2009: MicroRNAs: target recognition and regulatory functions. - Cell 136: 215-233 .

Catucci, I., Yang, R., Verderio, P., Pizzamiglio, S., Heesen, L., Hemminki, K., Sutter, C., Wappenschmidt, B., Dick, M., Arnold, N., Bugert, P., Niederacher, D., Meindl, A., Schmutzler, R.K., Bartram, C.C., Ficarazzi, F., Tizzoni, L., Zaffaroni, D., Manoukian, S., Barile, M., Pierotti, M.A., Radice, P., Burwinkel, B. and Peterlongo, P. 2010. Evaluation of SNPs in miR146a, miR196a2 and miR-499 as low-penetrance alleles in German and Italian familial breast cancer cases. - Hum. Mutat. 31: E1052-7.

Chen, C., Zhang, Y., Zhang, L., Weakley, S.M. and Yao, Q. 2011. MicroRNA-196: critical roles and clinical applications in development and cancer. - J. Cell Mol. Med. 15: 14-23.

Dumitrescu, R.G. and Cotarla, I. 2005. Understanding breast cancer risk - where do we stand in 2005? - J. Cell Mol. Med. 9: 208-221.

Fabbri, M., Valeri, N. and Calin, G.A. 2009. MicroRNAs and genomic variations: from Proteus tricks to Prometheus gift. - Carcinogenesis 30: 912917.

Filipowicz, W., Bhattacharyya, S.N. and Sonenberg, N. 2008. Mechanisms of post-transcriptional regulation by microRNAs: are the answers in sight? - Nat. Rev. Genet. 9: 102-114.

Gao, L.B., Bai, P., Pan, X.M., Jia, J., Li, L.J., Liang, W.B., Tang, M., Zhang, L.S., Wei, Y.G. and Zhang, L. 2011. The association between two polymorphisms in pre-miRNAs and breast cancer risk: a meta-analysis. Breast Cancer Res. Treat.125: 571-574.

Garzon, R., Calin, G.A. and Croce, C.M. 2009. microRNAs in cancer. - Annu. Rev. Med. 60:167-179

George, G.P., Gangwar, R., Mandal, R.K., Sankhwar, S.N. and Mittal, R.D. 2011. Genetic variation in microRNA genes and prostate cancer risk in North Indian population. - Mol. Biol. Rep. 38: 1609-1615.

Hoffman, A.E., Zheng, T., Yi, C., Leaderer, D., Weidhaas, J., Slack, F., Zhang, Y., Paranjape, T. and Zhu, Y. 2009. mcroRNA miR-196a-2 and breast cancer: a genetic and epigenetic association study and functional analysis. - Cancer Res. 15: 5970-5979.

Hosseinzadeh, M., Eivazi Ziaei, J., Mahdavi, N., Aghajari, P., Vahidi, M., Fateh, A. and Asghari, E. 2014. Risk factors for breast cancer in Iranian women: a hospital-based case-control study in Tabriz, Iran. - J. Breast Cancer 17: 236-243.

Hu, Z., Chen, J., Tian, T., Zhou, X., Gu, H., Xu, L., Zeng, Y., Miao, R., Jin, G., Ma, H., Chen, Y. and Shen, H. 2008. Genetic variants of miRNA sequences and non-small cell lung cancer survival. - J. Clin. Invest. 118: 2600-2608.

Hu, Z., Liang, J., Wang, Z., Tian, T., Zhou, X., Chen, J., Miao, R., Wang, Y., Wang, X. and Shen. H. 2009. Common genetic variants in pre-microRNAs were associated with increased risk of breast cancer in Chinese women. - Hum. Mutat. 30: 79-84.

Johnson, S.M., Grosshans, H., Shingara, J., Byrom, M., Jarvis, R., Cheng, A., Labourier, E., Reinert, K.L., Brown, D. and Slack, F.J. 2005. RAS is regulated by the let-7 microRNA family. - Cell 120: 635-647.

Landi, D., Gemignani, F. and Landi, S. 2012. Role of variations within microRNA-binding sites in cancer. Mutagenesis 27: 205-210.

Landi, D., Gemignani, F., Naccarati, A., Pardini, B., Vodicka, P., Vodickova, L., Novotny, J., Försti, A., Hemminki, K., Canzian, F. and Landi, S. 2008. Polymorphisms within micro-RNA-binding sites and risk of sporadic colorectal cancer. - Carcinogenesis 29: 579-584.

Lewis, B.P., Burge, C.B. and Bartel, D.P. 2005. Conserved seed pairing, often flanked by adenosines, indicates that thousands of human genes are microRNA targets. - Cell 120: 15-20.

Lin, P.Y. and Yang, P.C. 2011: Circulating miRNA signature for early diagnosis of lung cancer. - EMBO Mol. Med. 3: 436-437.

Linhares, J.J., Azevedo, M., Siufi, A.A., de Carvalho, C.V., Wolgien Mdel, C., Noronha, E.C., Bonetti, T.C. and da Silva, I.D. 2012. Evaluation of single nucleotide polymorphisms in microRNAs (hsa-miR-196a2 rs11614913 C/T) from Brazilian women with breast cancer. - BMC Med. Genet. 13:119. doi: 10.1186/1471-2350-13-119.

Miller, S.A., Dykes, D.D. and Polesky, H.F. 1988. A simple salting out procedure for extracting DNA from human nucleated cells. - Nucleic Acids Res.16: 12-15.

Mirtalebi, H., Heydari, N.M., Pourhoseingholi, M. and Asadzadeh-Aghdaei, H. 2014. Association of miR196a2 (rs11614t913) polymorphism with colorectal cancer in Tehran population. - Medical Science Journal of Islamic Azad University, Tehran Medical Branch 23: 11-15

Mousavi, S.M., Gouya, M.M., Ramazani, R., Davanlou, M., Hajsadeghi, N. and Seddighi, Z. 2009. Cancer incidence and mortality in Iran. - Ann. Oncol. 20: $556-563$ 
Okubo, M., Tahara, T., Shibata, T., Yamashita, H., Nakamura, M., Yoshioka, D., Yonemura, J., Ishizuka, T., Arisawa, T. and Hirata, I. 2010. Association between common genetic variants in pre-microRNAs and gastric cancer risk in Japanese population. Helicobacter 15: 524-531.

Otaghvar, H.A., Hosseini, M., Tizmaghz, A., Shabestanipour, G.H. and Noori, H. 2015. A review on metastatic breast cancer in Iran. - Asian Pac. J. Trop. Biomed. 5: 429-433.

Sadjadi, A., Nouraie, M., Ghorbani, A., Alimohammadian, M. and Malekzadeh, R. 2009. Epidemiology of breast cancer in the Islamic Republic of Iran: first results from a population-based cancer registry. - East Mediterr. Health J. 15: 1426-1431.

Saj, A. and Lai, E.C. 2011. Control of microRNA biogenesis and transcription by cell signaling pathways. - Curr. Opin. Genet. Dev. 21: 504-510.

Shastry, B.S. 2009. SNPs: impact on gene function and phenotype. - Methods Mol. Biol. 578: 3-22.

Srivastava, K., Srivastava, A. and Mittal, B. 2010. Common genetic variants in premicroRNAs and risk of gallbladder cancer in North Indian population. - J. Hum. Genet. 55: 495-499.
Vinci, S., Gelmini, S., Pratesi, N., Conti, S., Malentacchi, F., Simi, L., Pazzagli, M. and Orlando, C. 2011. Genetic variants in miR-146a, miR-149, miR196a2, miR-499 and their influence on relative expression in lung cancers. - Clin. Chem. Lab. Med. 49: 2073-2080.

Visone, R., Russo, L., Pallante, P., De Martino, I., Ferraro, A., Leone, V., Borbone, E., Petrocca, F., Alder, H., Croce, C.M. and Fusco, A. 2007. MicroRNAs (miR)-221 and miR-222, both overexpressed in human thyroid papillary carcinomas, regulate p27Kip1 protein levels and cell cycle. Endocr. Relat. Cancer 14: 791-798.

Wang, K., Guo, H., Hu, H., Xiong, G., Guan, X., Li, J., Xu, X., Yang, K. and Bai, Y. 2010. A functional variation in pre-microRNA-196a is associated with susceptibility of esophageal squamous cell carcinoma risk in Chinese Han. - Biomarkers 15: 614-618.

Yoon, K.A., Yoon, H., Park, S., Jang, H.J., Zo, J.I., Lee, H.S. and Lee, J.S. 2012. The prognostic impact of microRNA sequence polymorphisms on the recurrence of patients with completely resected non-small cell lung cancer. - J. Thorac. Cardiovasc. Surg. 144: 794780.

Eslami-Samarin, Z., Tahmaseb, M. and Ghaderi, A. 2015. Evaluation of single nucleotide polymorphism rs 11614913 in mir196a2 with breast cancer susceptibility in Southern Iranian population. - Nova Biologica Reperta 2: 227-234.

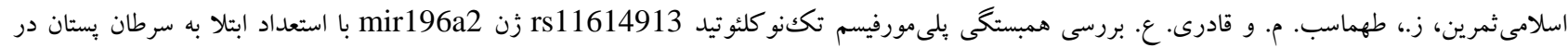

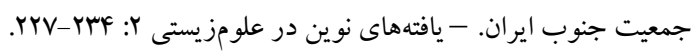


